\title{
REVIEW
}

\section{The double-edged role of nitric oxide in apoptosis signalling: focused on liver}

Tomáš Kučera

Institute of Histology and Embryology, First Faculty of Medicine, Charles University, Praha, Czech Republic

Received $4^{\text {th }}$ February 2004.

Revised $22^{\text {nd }}$ March 2004.

Published online $22^{\text {nd }}$ April 2004.

\begin{abstract}
Summary
Nitric oxide (NO) is a free radical endogenously produced by nitric oxide synthase. This molecule possesses many important functions in the mammalian organism. The role of NO in regulating cell death and proliferation is now widely recognized. In cultured primary hepatocytes both proapoptotic and antiapoptotic NO effects have been reported. However, most reports support its role in the inhibition of apoptosis. NO has been shown to suppress apoptosis in a model of inflammation and cholestasis, and inhibits spontaneous apoptosis. NO antiapoptotic function was exerted via inhibition of both activity and activation of caspases either directly by nitrosylation, or indirectly via an cGMP-dependent pathway. Both spontaneous and induced hepatocyte apoptosis can be determined by biochemical and morphological methods, which cover various aspects of the apoptotic process, and have a different specificity for detection of apoptotic cell death.
\end{abstract}

Keywords: cell proliferation - NO donor - caspase-3 - hepatotoxicity - TNF- $\alpha$

\section{PHYSIOLOGICAL ROLES OF NITRIC OXIDE}

During intensive research over the past 15 years, numerous functions have been attributed to $\mathrm{NO}-\mathrm{a}$ unique endogenously produced molecule. Most studies dealing with this free radical indicate its important role in the cardiovascular, nervous and immune systems. Well known is the NO-mediated vascular tone regulation (Ignarro et al. 1987), participation in nerve impulse transmission (Bredt and Snyder 1992) and the bactericidal effects of NO (Green et al. 1990). In addition to these recognized functions, there are many other regulatory pathways that are often surprisingly, reported to be under NO influence, as a growing number of scientists enter the field of NO research. For example, it has been recently suggested that $\mathrm{NO}$ has a role in the regulation of tight junction assembly in Sertoli cells (Lee et al. 2003).

\section{THE EFFECT OF NO ON CELL DEATH AND CELL PROLIFERATION}

In order to maintain tissue homeostasis, two key processes - cell proliferation and cell death should be kept in equilibrium. The balance between these two events, however, is set in a different manner for different tissues and time periods of development. Various regulatory pathways - or rather nets - have been described, where hormones, cytokines and other molecules (e.g. surface receptors) involved in cell-to-cell contact, interact to determine the fate of a particular cell. An important finding from $\mathrm{NO}$ 
research is the capability of this molecule to interfere with the cell cycle controlling mechanisms (Ishida et al. 1997). When studying NO effects on cell proliferation and death two different aspects must be considered, i.e. the physiological and the pathological. In relation to these two aspects, it is also important to distinguish between the effects of $\mathrm{NO}$ as a signalling molecule and the side effects of $\mathrm{NO}$, produced primarily to carry out functions disconnected from the cell cycle regulation, such as the anti-microbial defence (Kilbourn et al. 1991). Since the amount of local NO production was shown to be an important variable in determining the cell's fate, it should be considered which nitric oxide synthase (NOS) isoform is acting in any particular situation (Ou et al. 1997). Neuronal (nNOS) and endothelial (eNOS) are expressed constitutively in their more or less typical localization and both produce a relatively small amount of NO (Billiar 1995). In contrast, inducible (iNOS) is expressed in a given tissue as a response to certain stimuli (Geller et al. 1993). The amount of NO produced by this isoform is comparatively very high. Regardless of its source in a particular organ or tissue, NO has to be produced close to its target, since it is a short-lived molecule. As was already suggested, the context of NO production is important for the result of its interaction with cellular functions. NO is a free radical and as such it could be toxic if the oxidoreductive situation favours its transformation to even more harmful intermediates like peroxynitrite (Murphy 1999).

It has been repeatedly demonstrated, that NO could either stimulate or inhibit cell proliferation. For instance, the direct influence of the cell cycle regulating protein expression was documented during the inhibition of vascular smooth muscle cell proliferation (Kibbe et al. 2000). The stimulatory effect on cell proliferation, on the other hand, was noted in liver. Since hepatocytes in normal liver are in a quiescent state, it is necessary, for proliferation to occur, that the cells are primed to respond to mitogenic signals conveyed by appropriate cytokines (Court et al. 2002). NO has been shown to switch hepatocytes to a hepatocyte growth factor responsive state. This was accomplished through the down-regulation of S-adenosylmethionine levels (García - Trevijano et al. 2002).

The interaction of $\mathrm{NO}$ with the apoptotic machinery was noted in a number of cells and tissues. Both proapoptotic and antiapoptotic NO effects were reported. NO induced apoptosis in macrophages (Albina et al. 1993; Sarih et al. 1993), pancreatic $\beta$-cells (Kaneto et al. 1995), thymocytes (Fehsel et al. 1995), neurons (Liu et al. 2001; Palluy and Rigaud 1996) and some tumour cells. In contrast the antiapoptotic action of NO was reported in human B-lymphocytes (Mannick et al. 1994), endothelial cells (Dimmeler et al. 1997), cardiomyocytes (Cheng et al. 1995), splenocytes (Genaro et al. 1995) and ovarian follicles (Chun et al. 1995). The role of NO in the regulation of hepatocyte apoptosis is the subject of the present article.

\section{NO IN LIVER BIOLOGY}

Normally, only the constitutive eNOS isoform is present in the liver where it supports the maintenance of an adequate blood circulation (Wiest and Groszmann 2002). The amount of NO produced under standard conditions is small. During liver injury, another isoform - iNOS - is upregulated as a defence mechanism. The adverse conditions stimulating iNOS expression are endotoxemia, hemorrhagic shock, ischemia-reperfusion, sepsis, infection, hepatitis, exposure to ozone, production of reactive oxygen species and liver regeneration $(\mathrm{Li}$ and Billiar 1999). As soon as it is expressed, iNOS starts to synthesise great amounts of NO that become a significant regulator of inflammatory response during infection. The expression of iNOS in hepatocytes and non-parenchymal Kupffer cells is induced by lipopolysaccharide (LPS), tumour necrosis factor - alpha (TNF- $\alpha)$, interleukin $-1 \beta$ (IL-1 $\beta)$ and interferon $-\gamma($ IFN- $\gamma)$ as well as by the synergic effects of these cytokines (Geller et al. 1993). Liver endothelial cells and Ito cells are also capable of NO synthesis by iNOS (Helyar et al. 1994, Spitzer 1994). Thus, during inflammation, liver parenchymatous cells are situated in a milieu where NO is synthesised by hepatocytes and also by their neighbouring cells.

\section{METHODS AND EXPERIMENTAL DESIGN IN NO RESEARCH}

For the study of NO-induced effects in liver both in vivo and in vitro the following methodological approaches are utilized. The animal or cultured cells can be induced to synthesise NO. Either the cells are stimulated to produce endogenous NO by their own NOS isoform or are transfected with a gene for iNOS (Tzeng et al. 1998). There is also the possibility of using a NO releasing drug to supply cells or the whole organism with exogenous NO. Several NO releasing substances - NO donors - are used that differ in important properties like the kinetics of NO release, stability, membrane permeability, toxicity and also applicability to either in vivo or in vitro experiments. On the other hand, when the objective is to study some process in the context of a diminished NO level, various inhibitors 
of NOS can be used. These inhibitors are characterised by their selectivity to a particular NOS isoform (Muscará and Wallace 1999).

Cell cultures provide a useful model for studying NO induced effects on hepatocytes. The majority of published papers deal with primary rat hepatocytes (García - Trevijano et al. 2002, Joshi et al. 1999). The advantage of this model is its relevance to the in vivo situation (since these are non-transformed cells that maintain a great deal of their natural character) and the possibility of influencing the liver cell population that we are interested in here. It should be mentioned that they are easily obtained in contrast to human hepatocytes. The disadvantages are the limited time period during which the cells can be kept without significant cell degeneration and obvious differences with respect to the human hepatocyte physiology.

\section{BENEFICIAL AND DETRIMENTAL EFFECTS OF NO IN THE LIVER}

As has been stated already, both cytoprotective and cytotoxic NO-induced effects can be encountered ( $\mathrm{Li}$ and Billiar 1999). The same is true for the role of this molecule in the liver. Regarding its effect on liver perfusion, NO produced by eNOS is generally considered to be protective (Wiest and Groszmann 2002). However, the results of iNOS activation during various kinds of hepatic injury are quite contradictory. It was demonstrated that NO protected the liver in endotoxemia (Farghali et al. 2003), liver regeneration (Rai et al. 1998), after the simultaneous application of TNF- $\alpha$ and D-galactosamine (Saavedra et al. 1997) or during carbon tetrachloride induced liver injury where oxidative stress was reduced (Muriel 1998). In another experimental model of endotoxemia, however, NO worsened oxidative injury and induced circulatory failure (Thiemermann et al. 1995). Detrimental properties of NO were also registered during hemorrhagic shock and ischemia-reperfusion (Hierholzer et al. 1998).

\section{NO AND APOPTOSIS IN THE LIVER}

Apoptosis occurs in the liver as a physiological mechanism for maintaining a constant cell number, but more frequently during various pathological conditions. An increased incidence of apoptotic cell demise can be found in alcoholic liver disease (Goldin et al. 1993), viral hepatitis (Rivero et al. 1998), cholestasis (Patel et al. 1994), liver failure (Strand et al. 1998), and after intoxication (Cascales et al. 1994). On the other hand, the resistance to apoptotic stimuli has been implicated as an important factor in hepatocarcinogenesis (Ito et al. 1998). The question of how NO affects apoptosis during various kinds of liver injury is a very important aspect of the role NO in this organ and determines whether its effect will be beneficial or detrimental.

\section{NO EFFECTS ON APOPTOSIS IN VIVO}

In endotoxemic rats the administration of selective inhibitors of iNOS resulted in an increase of apoptosis as determined by both the DNA Fragment assay and the TUNEL method (Ou et al. 1997). The antiapoptotic effect of NO was observed in the Salmonella infection of mice who were both wild and iNOS deficient In iNOS knock-out animals there was an increase of the apoptotic cell count compared to wild-type animals which were probably protected by the bactericidal NO effect (Alam et al. 2002). After partial hepatectomy, mice having the iNOS gene knocked-out displayed heavy impairment of liver regeneration.

This severe inability to restore previous liver mass was caused in these iNOS lacking animals, by, among other factors, a large-scale hepatocyte cell death (Rai et al. 1998). When the liver specific NO releasing drug V-PYRRO/NO was administered to rats treated with $\mathrm{TNF}-\alpha+\mathrm{D}$-galactosamine, protection against hepatotoxicity and apoptosis was achieved to a significant degree (Saavedra et al. 1997). The same drug dramatically reduced LPS/Dgalactosamine-induced hepatotoxicity and simultaneously suppressed caspase-3 activity during liver injury in mice (Liu et al. 2002).

\section{NO EFFECTS ON APOPTOSIS IN VITRO}

Substantial progress has been made in in vitro models of NO influence on apoptosis. Several experiments have been performed on murine and human cultured hepatocytes. However, rat hepatocytes have been the most studied so far (Gumpricht et al. 2002, Kim et al. 1997a, Schoemaker et al. 2002). The effect of NO was studied in primary rat hepatocytes during spontaneous apoptosis of cells in vitro and after the induction of apoptosis.

Several papers report on the apoptosis inducing effect of NO donated by sodium nitroprusside (SNP). After $24 \mathrm{~h}, \mathrm{SNP}(0,5 \mathrm{mM})$ caused hepatocyte cell injury characterized by a hepatocyte enzyme release into the culture medium. Hepatocyte cell 
death was documented as an increase of cells with hypodiploid DNA content measured by flow cytometry after propidium iodide staining and also as an elevated percentage of cytosolic DNA fragments quantitated by ELISA kit (Wang et al. 1998). The methods used in this work and simultaneous signs of necrosis, raise concerns about the actual mode of SNP-induced cell death. Also the potential side effects of this substance on hepatocyte viability could not be excluded.

In contrast, a number of authors support the antiapoptotic action of NO. The inhibitory effect on hepatocyte apoptosis was documented after programmed cell death was induced by the combination of TNF- $\alpha$ and actinomycin D (ActD). Cells that were pretreated with a $750 \mu \mathrm{M}$ concentration of NO-donor S-nitroso-N-acetyl penicillamine (SNAP) several hours before the addition of TNF- $\alpha$ and actinomycin D, were protected against hepatotoxicity and apoptosis. It was also suggested that NO-induced tolerance towards TNF- $\alpha$-mediated toxicity was related to heat shock protein 70 expression (Kim et al. 1997a).

In another study the hepatoprotection by NO was demonstrated in spontaneous apoptosis after four days of culture (Kim et al. 1997b). The spontaneous loss of viability was reversed by adding the NO donors SNAP and V-PYRRO/NO or by stimulating cells to express iNOS in response to cytokine combination (IL-1 $\beta$ and IFN- $\gamma$ ). Hepatoprotection was further manifested by the inhibition of caspase-3 activity. Poly (ADP-ribose) polymerase degradation was prevented in cytokine treated cultures. The suppression of caspase- 3 activity by NO donors was in this study further documented in TNF- $\alpha$ and ActD-induced apoptosis. The suggested NO-mediated antiapoptotic mechanism was the inhibition of caspase-3 activity by S-nitrosylation of cysteine residue in the catalytic site of enzyme and by the cGMP-dependent pathway.

These results were confirmed by another paper from the same authors who presented data on further events involved in NO inhibition of TNF- $\alpha$ and ActD-induced apoptosis ( $\mathrm{Li}$ et al. 1999). SNAP blocked the cleavage/activation of pro-caspase- 3 in TNF- $\alpha+$ ActD treated cells. Changes in the mitochondrial function during apoptosis were also influenced. Co-incubation of SNAP with apoptotic inducers suppressed the disruption of the mitochondrial transmembrane potential and the level of cytosolic cytochrome c was brought back down to control levels. SNAP exerted its effect also through another component of TNF- $\alpha$ apoptosis inducing pathway - caspase- 8 - as both its activity and its activation/cleavage were inhibited by this NO donor.Endogenous NO production was in this study achieved by adenoviral iNOS gene transfer.
Transfected cells were protected against apoptosis caused by TNF- $\alpha+A c t D$. In addition, caspase- 3 activity, processing of pro-caspase- 3 and PARP cleavage were suppressed. Another study showed that in cultures treated with the combination of TNF- $\alpha$, IL- $1 \beta$, IFN- $\gamma$, LPS and ActD caspase-3 activity was inhibited by V-PYRRO/NO (Schoemaker et al. 2002).

Above-mentioned examples of NO antiapoptotic effects were studied on models of hepatic injury caused by cytokines that are expressed during inflammation and hepatic failure. However, similar results were obtained in cultures treated with hydrophobic bile acid glycochenodeoxycholate (GCDCA) as a simulation of cholestatic liver injury (Gumpricht et al. 2002). NO donors SNAP and spermine-NONOate (SNN) suppressed apoptosis and decreased caspase-3 activity in hepatocytes exposed to $100 \mu \mathrm{M}$ GCDCA, but bile acid-induced mitochondrial depolarisation remained unaffected by NO treatment.

\section{CONCLUSION}

It can be concluded that the majority of studies published in the last several years support the antiapoptotic effect of both endogenous and exogenous NO in primary rat hepatocytes. So far the antiapototic effect of NO has been documented in models simulating inflammatory and cholestatic hepatocyte injury. In further research it would be useful to examine also the effects on liver cell apoptosis caused by other factors e.g. drugs, toxins, ethanol and its metabolites. Also it would be important to utilize new methods of apoptosis detection in order to discriminate between various types of cell death and to explore apoptotic pathways potentially influenced by NO.

As has been already shown, there are a number of levels where NO is known to act when inhibiting apoptosis: the direct inhibition of caspase activity as well as caspase activation by S-nitrosylation; the indirect effect via NO "classics" - the cGMP dependent pathway; induction of intrinsic defence mechanisms such as synthesis of heat shock proteins, and probably other mechanisms that may play a role in different ways of apoptosis induction. Clearly, despite the significant amount of data presented in the above discussed studies, this field remains open for further research.

\section{ACKNOWLEDGEMENTS}

This work was supported by the Grant $5 / 2002 / \mathrm{C}$ of the Grant Agency of Charles University and the 
Research Project J 13/98 111100002-6 of the Ministry of Education, Youth and Sports of the Czech Republic.

\section{REFERENCES}

Alam M.S., T. Akaike, S. Okamoto, T. Kubota, J. Yoshitake, T. Sawa, Y. Miyamoto, F. Tamura, H. Maeda: Role of nitric oxide in host defense in murine salmonellosis as a function of its antibacterial and antiapoptotic activities. Infect. Immun. 70: 3130-3142, 2002.

Albina J., S. Cui, R. Mateo, J. Reichner: Nitric oxide-mediated apoptosis in murine peritoneal macrophages. J. Immunol. 150: 5080-5085, 1993.

Billiar T.R.: Nitric oxide: Novel biology with clinical relevance. Ann. Surg. 221: 339-349, 1995.

Bredt D.S. and S.H. Snyder: Nitric oxide, a novel neuronal messenger. Neuron 8: 3-11, 1992.

Cascales M., A. Alvarez, P. Gasco, L. FernandezSimon, N. Sanz, L. Bosca: Cocaine-induced liver injury in mice elicits specific changes in DNA ploidy and induces programmed death of hepatocytes. Hepatology 20: 992-1001, 1994.

Cheng W., B. Li, J. Kajstura, P. Li, M.S. Wolin, E.H. Sonnenblick, T.H. Hintze, G. Olivetti, P. Anversa: Stretch-induced programmed myocyte cell death. J. Clin. Invest. 96: 22472259, 1995.

Chun S.J., K.M. Eisenhauer, M. Kubo, A.J.W. Hsueh: Interleukin-1 $\beta$ suppresses apoptosis in rat ovarian follicles by increasing nitric oxide production. Endocrinology 136: 3120-3127, 1995.

Court F.G., S.A. Wemyss-Holden, A.R. Dennison, G.J. Maddern: The mystery of liver regeneration. Br. J. Surg. 89: 1089-1095, 2002.

Dimmeler S., J. Haendeler, M. Nehls, A.M. Zeiher: Suppression of apoptosis by nitric oxide via inhibition of interleukin-1beta-converting enzyme (ICE)-like and cysteine protease protein (CPP)32-like proteases. J. Exp. Med. 185: 601-608, 1997.

Farghali H., N. Canová, T. Kučera, J. Martínek, K. Mašek: Nitric oxide synthase inhibitors modulate lipopolysaccharide-induced hepatocyte injury: dissociation between in vivo and in vitro effects. Int. Immunopharmacol. 3: 1627-1638, 2003.

Fehsel K., K.D. Kröncke, K.L. Meyer, H. Huber, V. Wahn, V. Kolb-Bachofen: Nitric oxide induces apoptosis in mouse thymocytes. J. Immunol. 155: 2858-2865, 1995.
García-Trevijano E.R., M.L. Martínez-Chantar, M.U. Latasa, J.M. Mato, M.A. Avila: NO sensitizes rat hepatocytes to proliferation by modifying S-Adenosylmethionine levels. Gastroenterology 122: 1355-1363, 2002.

Geller D.A., A.K. Nussler, M.Di Silvio, C..J. Lowenstein, R.A. Shapiro, S.C. Wang, R.L. Simmons, T.R. Billiar: Cytokines, endotoxin, and glucocorticoids regulate the expression of inducible nitric oxide synthase in hepatocytes. Proc. Natl. Acad. Sci. USA 90: 522-526, 1993.

Genaro A.M., S. Hortelano, A. Alvarez, C. Martinez, L. Bosca: Splenic B lymphocyte programmed cell death is prevented by nitric oxide release through mechanisms involving sustained Bcl-2 levels. J. Clin. Invest. 95: 18841890, 1995.

Goldin R.D., N.C. Hunt, J. Clark, S.N. Wickrmasinghe: Apoptotic bodies in a murine model of alcoholic liver disease: reversibility of ethanol-induced changes. J. Pathol. 171: 73-76, 1993.

Green S.J., M.S. Meltzer, J.B. Hibbs Jr, C.A. Nacy: Activated macrophages destroy intracellular Leishmania major amastigotes by an L-argininedependent killing mechanism. J. Immunol. 144: 278-283, 1990.

Gumpricht E., R. Dahl, B. Yerushalmi, M.W. Devereaux, R.J. Sokol: Nitric oxide ameliorates hydrophobic bile acid-induced apoptosis in isolated rat hepatocytes by non-mitochondrial pathways. J. Biol. Chem. 277: 25823-25830, 2002.

Helyar L., D.S. Bundschuh, J.D. Laskin, D.L. Laskin: Induction of hepatic Ito cell nitric oxide production after acute endotoxemia. Hepatology 20: 1509-1515, 1994.

Hierholzer C., B. Harbrecht, J.M. Menezes, J. Kane, J. MacMicking, C.F. Nathan, A.B. Peitzman, T.R. Billiar, D.J. Tweardy: Essential role of induced nitric oxide in the initiation of the inflammatory response after hemorrhagic shock. J. Exp. Med. 187: 917-928, 1998.

Ignarro L.J., G.M. Buga, K.S. Wood, R.E. Byrns, G. Chaudhuri: Endothelium-derived relaxing factor produced and released from artery and vein is nitric oxide. Proc. Natl. Acad. Sci. USA 84: 9265-9269, 1987.

Ishida A., T. Sasaguri, C. Kosaka, H. Nojima, J. Ogata: Induction of the cyclin-dependent kinase inhibitor p21Sdi1/Cip1/Waf1 by nitric oxide-generating vasodilator in vascular smooth muscle cells. J. Biol. Chem. 272: 10050-10057, 1997.

Ito Y., T. Takeda, K. Umeshita, M. Sakon, K. Wakasa, N. Matsuura, M. Monden: Fas 
antigen expression in hepatocellular carcinoma tissues. Oncol. Rep. 1: 41-44, 1998.

Joshi M. S., J.L. Ponthier, J.R. Lancaster Jr: Cellular antioxidant and pro-oxidant actions of nitric oxide. Free. Radic. Biol. Med. 27: 135766, 1999.

Kaneto H., J. Fujii, H.G. Seo, K. Suzuki, T. Matsuoka, M. Nakamura, H. Tatsumi, Y. Yamasaki, T. Kamada, N. Taniguchi: Apoptotic cell death triggered by nitric oxide in pancreatic beta-cells. Diabetes 44: 733-738, 1995.

Kibbe M.R., J. Li, S. Nie, S.C. Watkins, A. Lizonova, I. Kovesdi, R.L. Simmons, T.R. Billiar , E. Tzeng: Inducible nitric oxide synthase (iNOS) expression upregulates p21 and inhibits vascular smooth muscle cell proliferation through p42/44 mitogen - activated protein kinase activation and independent of p53 and cyclic guanosine monophosphate. J. Vasc. Surg. 31: 1214-1228, 2000.

Kilbourn R.G., A. Jubran, S.S. Gross, O.W. Griffith, R. Levi, J. Adams, R.F. Lodato: Reversal of endotoxin-mediated shock by NGmethyl-L-arginine, an inhibitor of nitric oxide synthesis. Biochem. Biophys. Res. Commun. 172: 1132-1138, 1991.

Kim Y.M., M. E. de Vera, S.C. Watkins, T.R. Billiar: Nitric oxide protects cultured rat hepatocytes from tumor necrosis factor- $\alpha$ induced apoptosis by inducing heat shock protein 70 expression. J. Biol. Chem. 272: 1402-1411, $1997 \mathrm{a}$.

Kim Y.M., R.V. Talanian, T.R. Billiar: Nitric oxide inhibits apoptosis by preventing increases in caspase-3-like activity via two distinct mechanisms. J. Biol. Chem. 272: 31138-31148, $1997 b$.

Lee N.P.Y., C.Y. Cheng: Regulation of Sertoli cell tight junction dynamics in the rat testis via the nitric oxide synthase/soluble guanylate cyclase/3',5'-cyclic guanosine monophosphate/ protein kinase $\mathrm{G}$ signaling pathway: An in vitro study. Endocrinology 144: 3114-3129, 2003.

Li J. and T.R. Billiar: Nitric Oxide IV. Determinants of nitric oxide protection and toxicity in liver. Am. J. Physiol. 276: G1069G1073, 1999.

Li J., C.A. Bombeck, S. Yang, Y.M. Kim, T.R. Billiar: Nitric oxide suppresses apoptosis via interrupting caspase activation and mitochondrial dysfunction in cultured hepatocytes. J. Biol. Chem. 274: 17325-17333, 1999.

Liu J., J.E. Saavedra, T. Lu, J.G. Song, J. Clark, M.P. Waalkes, L.K. Keefer: O2-Vinyl 1-(pyrrolidin-1-yl) diazen-1-ium-1, 2-diolate protection against D-galactosamine/endotoxin- induced hepatotoxicity in mice: Genomic analysis using microarrays. J. Pharmacol. Exp. Ther. 300: 18-25, 2002.

Liu Z., L.J. Martin: Motor neurons rapidly accumulate DNA single-strand breaks after in vitro exposure to nitric oxide and peroxynitrite and in vivo axotomy. J. Comp. Neurol. 432: 3560, 2001.

Mannick J.B., K. Asano, K. Izumi, E. Kieff, J.S. Stamler: Nitric oxide produced by human B lymphocytes inhibits apoptosis and Epstein-Barr virus reactivation. Cell 79: 1137-46, 1994.

Muriel P.: Nitric oxide protection of rat liver from lipid peroxidation, collagen accumulation, and liver damage induced by carbon tetrachloride. Biochem. Pharmacol. 56: 773-779, 1998.

Murphy M.P.: Nitric oxide and cell death. Biochim. Biophys. Acta 1178: 153-175, 1993.

Muscará M.N., J.L. Wallace: Nitric Oxide V. Therapeutic potential of nitric oxide donors and inhibitors. Am. J. Physiol. 276: G1313G1316, 1999.

Ou J., T.M. Carlos, S.C. Watkins, J.E. Saavedra, L.K. Keefer, Y.M. Kim, B.G. Harbrecht, T.R. Billiar: Differential effects of nonselective nitric oxide synthase (NOS) and selective inducible NOS inhibition on hepatic necrosis, apoptosis, ICAM-1 expression, and neutrophil accumulation during endotoxemia. Nitric Oxide 1: 404-416, 1997.

Palluy O., M. Rigaud: Nitric oxide induces cultured cortical neuron apoptosis. Neurosci. Lett. 208: 1-4, 1996.

Patel T., S.F. Bronk, G.J. Gores: Increases of intracellular magnesium promote glycodeoxycholate - induced apoptosis in rat hepatocytes. J. Clin. Invest. 94: 2183-2192, 1994.

Rai R.M., F.Y.J. Lee, A. Rosen, S.Q. Yang, H.Z. Lin, A. Koteish, F.Y. Liew, C. Zaragoza, C. Lowenstein, A.M. Diehl: Impaired liver regeneration in inducible nitric oxide synthasedeficient mice. Proc. Natl. Acad. Sci. USA 95: 13829-13834, 1998.

Saavedra J.E., T.R. Billiar, D.L. Williams, Y.M. Kim, S.C. Watkins, L.K. Keefer: Targeting nitric oxide (NO) delivery in vivo. Design of a liver-selective NO donor prodrug that blocks tumor necrosis factor-alpha-induced apoptosis and toxicity in the liver. J. Med. Chem. 40: 1947-54, 1997.

Sarih M., V. Souvannavong, A. Adam: Nitric oxide synthase induces macrophage death by apoptosis. Biochem. Biophys. Res. Commun. 191: 503508, 1993.

Schoemaker M.H., J.E. Ros, M. Homan, C. Trautwein, P. Liston, K. Poelstra, H. van Goor, P.L.M. Jansen, H. Moshage: Cytokine 
regulation of pro- and anti-apoptotic genes in rat hepatocytes: NF- $\kappa \mathrm{B}$-regulated inhibitor of apoptosis protein 2 (cIAP2) prevents apoptosis. J. Hepatol. 36: 742-750, 2002.

Spitzer J. A.: Cytokine stimulation of nitric oxide formation and differential regulation in hepatocytes and nonparenchymal cells of endotoxemic rats. Hepatology 19: 217-228, 1994.

Strand S., W.J. Hofmann, A. Grambihler, H. Hug, M. Volkmann, G. Otto, H. Wesch, S.M. Mariani, V. Hack, W. Stremmel, P.H. Krammer, P.R. Galle: Hepatic failure and liver cell damage in acute Wilson's disease involve CD95 (APO$1 /$ Fas) mediated apoptosis. Nature Med. 4(5): 588-593, 1998.

Thiemermann C., H. Ruetten, C.C. Wu, J.R. Vane: The multiple organ dysfunction syndrome caused by endotoxin in the rat: attenuation of liver dysfunction by inhibitors of nitric oxide synthase. Br. J. Pharmacol. 116: 2845-2851, 1995.

Tzeng E., T.R. Billiar, D.L. Williams, J. Li, A. Lizonova, I. Kovesdi, Y.M. Kim: Adenovirus - mediated inducible nitric oxide synthase gene transfer inhibits hepatocyte apoptosis. Surgery 124: 278-283, 1998.

Wang J.H., H.P. Redmond, Q.D. Wu, D.BouchierHayes: Nitric oxide mediates hepatocyte injury. Am. J. Physiol. 275: G1117-G1126, 1998.

Wiest R. and R.J. Groszmann: The paradox of nitric oxide in cirrhosis and portal hypertension: too much, not enough. Hepatology 35: 478-491, 2002.

\section{Address:}

Tomáš Kučera, Institute of Histology and Embryology, First Faculty of Medicine, Charles University, Albertov 4, Praha 2, 12801, Czech Republic, tkucer@1f1.cuni.cz 